Artículo Original/ Original Article

http://dx.doi.org/10.18004/mem.iics/1812-9528/2021.019.02.32

\title{
Implementación de un sistema de detección de flavivirus en mosquitos
}

\author{
Fátima Cardozo ${ }^{(i)}{ }^{1}$, Alejandra Rojas $(i D)$, Cynthia Bernal $(i D)$, Luis Ferreira $(i D)$, \\ Adrián Díaz ${ }^{(\mathbb{D} 3}$, Malvina Páez ${ }^{\mathbb{D} 1}$, Yvalena Guillén ${ }^{(D)}$, Marta Contigiani ${ }^{3}$, \\ Laura Mendoza (iD) ${ }^{*}$
}

${ }^{1}$ Universidad Nacional de Asunción (UNA), Instituto de Investigaciones en Ciencias de la Salud (IICS). San Lorenzo, Paraguay

${ }^{2}$ Ministerio de Salud Pública y Bienestar Social, Servicio Nacional de Erradicación al Paludismo (SENEPA). Asunción, Paraguay

${ }^{3}$ Universidad Nacional de Córdoba, Facultad de Ciencias Médicas, Instituto de Virología "Dr. J.M. Vanella". Córdoba, Argentina

Cómo referenciar este artículo/ How to reference this article:
Cardozo F, Rojas A, Bernal C, Ferreira L, Díaz $\boldsymbol{A}$, Páez $\mathbf{M}$, et al. Implementación de un sistema de detección de flavivirus en mosquitos. Mem. Inst. Investig. Cienc. Salud. 2021; 19(2): 32-40

\begin{abstract}
RES U M E N
Los Flavivirus constituyen virus transmitidos por artrópodos, principalmente mosquitos. Pueden producir enfermedades en humanos y animales, también incluyen virus específicos de insectos que solo infectan y se replican en los insectos, no así en vertebrados. En Paraguay los virus dengue, fiebre amarilla y Zika fueron detectados en infecciones humanas, pero los estudios de flavivirus en mosquitos son aún escasos. Por ello, el objetivo del presente estudio fue implementar un sistema de detección de flavivirus en mosquitos en el IICS-UNA. Primero, se organizaron capacitaciones en colecta, preparación de pools y procesamiento por técnicas de RT-PCRs convencionales realizadas por expertos internacionales a profesionales locales (bioquímicos y biólogos). Además, se implementaron planillas de registro de datos y de control de transporte de muestras de los lugares de colectas hasta el IICS-UNA. Se prepararon en total 201 pools de 1 a 35 mosquitos cada uno agrupados por especie, localidad, entre otros criterios. Para asegurar la integridad del RNA extraído se realizó la detección de un control interno (Actina-1), siendo todos los pools positivos para el mismo, 91/201 pools fueron positivos para flavivirus. Se realizó la secuenciación de $19 / 91$ pools positivos para flavivirus identificándose flavivirus de insectos (detectándose principalmente Culex Flavivirus, cell fusing agents Flavivirus y Kamiti river virus), evidenciando la elevada distribución de estos virus. Estos resultados demuestran que fue factible implementar el sistema de detección de flavivirus en mosquitos, lo cual podría contribuir a fortalecer la vigilancia y control de estas virosis, así como el conocimiento sobre la importancia ecológica de flavivirus de insectos.
\end{abstract}

Palabras clave: flavivirus, mosquitos, RT-PCRs, Paraguay

\section{Implementation of a flavivirus detection system in mosquitoes}

\footnotetext{
A B S T R A C T

Flaviviruses are viruses transmitted by arthropods, mainly mosquitoes. They can cause diseases in humans and animals, they also include specific insect viruses that only infect and replicate in insects, not in vertebrates. In Paraguay, dengue, yellow

Fecha de recepción: Junio 2021. Fecha de aceptación: Julio 2021

*Autor correspondiente: Prof. Laura Mendoza, MSc, PhD, Instituto de Investigaciones en Ciencias de la Salud, Universidad Nacional de Asunción, San Lorenzo, Paraguay.

Email: lauramendozatorres@gmail.com
} 
fever, and Zika viruses were detected in human infections, but studies of flaviviruses in mosquitoes are still scarce. Therefore, the objective of the present study was the implementation of a flavivirus detection system in mosquitoes at IICS-UNA. First, trainings on collection, pool preparation and processing by conventional RT-PCR techniques were organized by international experts for local professionals (biochemists and biologists). In addition, data log sheets and sample transport control forms from the collection sites to the IICS were implemented. A total of 201 pools of 1 to 35 mosquitoes were prepared, each grouped by species, locality, among others. To ensure the integrity of the extracted RNA, an internal control (Actin-1) detection was performed, all pools being positive for it; 91/201 pools were positive for flaviviruses. The sequencing of $19 / 91$ pools positive for flavivirus was carried out, identifying flavivirus in all cases of insects (mainly detecting Culex Flavivirus, cell fusing agents Flavivirus and Kamiti river virus), evidencing the high distribution of these viruses. These results demonstrate that it was feasible to implement the flavivirus detection system in mosquitoes, which could contribute to strengthen the detection, surveillance and control of these viruses, as well as, the knowledge about the ecological importance of insect flaviviruses.

Keywords: flaviviruses, mosquitoes, RT-PCRs, Paraguay

\section{INTRODUCCIÓN}

La familia Flaviviridae comprende aproximadamente 60 especies de virus diferentes, y se encuentra conformada por varios géneros, de los cuales, 53 especies corresponden al género Flavivirus, entre ellos, los de mayor importancia en la salud pública son los virus dengue (DENV), encefalitis de San Luis (SLEV), fiebre amarilla (YFV), Nilo Occidental (WNV) y Zika (ZIKV) ${ }^{(1)}$. Los flavivirus se transmiten a través de mosquitos o garrapatas, e incluyen agentes patógenos para los seres humanos y los animales ${ }^{(2)}$. Son responsables de provocar una considerable morbilidad y mortalidad en humanos; llevando a causar desde infecciones febriles leves a graves como encefalitis, síndromes hemorrágicos y hepatitis ${ }^{(3,4)}$. Los flavivirus también pueden ser virus específicos de insectos (ISFV), que no pueden infectar a vertebrados. Los ISFV constituyen un desafío para la mejor comprensión del ciclo de transmisión de los virus transmitidos por artrópodos, arbovirus ${ }^{(5)}$.

Los flavivirus de importancia médica requieren de tres actores esenciales para establecer y mantener un ciclo de transmisión: el virus, el artrópodo, y los vertebrados. Como requisito previo para la circulación continua del virus entre el vector artrópodo y hospedador vertebrado, todos los factores deben estar disponibles en número suficiente, al mismo tiempo y en el mismo lugar ${ }^{(6)}$.

Uno de los aspectos más importantes para el control de las enfermedades transmitidas por arbovirus es la disponibilidad de sistemas de detección sensibles, específicos que permitan determinar el nivel de actividad viral para, de este modo, diseñar, desarrollar y aplicar sistemas de vigilancia eficaces, así como sistemas de diagnóstico de infección en humanos y animales que permitan la toma de medidas adecuadas para minimizar los efectos de la infección ${ }^{(7)}$.

Los flavivirus de impacto sanitario para nuestra región incluyen al DENV que provoca una variedad de síntomas desde sin signos de alarma hasta dengue grave, el YFV productor de enfermedad febril con hemorragias e ictericia y el ZIKV. También en la región han sido detectados otros flavivirus, tales como SLEV, WNV y virus Ilheus $(\text { ILHV) })^{(8-12)}$.

En el Paraguay, los flavivirus reportados son DENV, YFV y ZIKV. El dengue es endémico en el país donde han sido detectados casos clínicos desde 1988 y ha causado grandes epidemias a lo largo de los años. Mientras que de ZIKV se han reportado casos confirmados desde el 2015. Estos flavivirus se encuentran circulando simultáneamente desde el 2015 hasta la actualidad. Por otro lado, en nuestro país también fue detectada la circulación del YFV, observándose en el año 2008, 24 casos confirmados de infecciones con 8 muertes ${ }^{(13)}$.

Tanto el DENV, ZIKV y YFV son trasmitidos por mosquitos del género Aedes (aegypti, albopictus, polynesiensis y scutelaris), siendo en Paraguay, el principal 
vector el Aedes aegypti, especie doméstica que se desarrolla en una amplia variedad de criaderos ${ }^{(14,15)}$. Aún no existen reportes de circulación de otros flavivirus en nuestro país.

Paraguay constituye un sitio que reúne las condiciones apropiadas para permitir la circulación de numerosos flavivirus que aún no han sido reportados pero que circulan de manera autóctona en países limítrofes como Brasil y Argentina. Datos no publicados proporcionados por el Departamento de Entomología del Servicio Nacional de Erradicación del Paludismo (SENEPA) describieron una gran variedad de especies de mosquitos, aproximadamente 90 especies como Culex quinquefasciatus, Culex pipiens, Culex nigripalpus, entre otros. Los mismos podrían actuar como vectores de estas virosis ${ }^{(16)}$.

Existen varias técnicas moleculares (RT-PCR) que permiten la detección del RNA de los flavivirus con alta sensibilidad y especificidad, las cuales pueden utilizar primers universales genéricos para regiones como NS5 que pueden detectar presencia de infección por cualquier flavivirus o primers específicos para detección de infección por DENV, YFV, entre otros ${ }^{(17-20)}$.

En un estudio previo realizado en Paraguay en el 2017, se estandarizó una técnica descripta previamente por Sánchez-Seco de RT-nested PCR genérica para detección de flavivirus que utiliza oligonucleóticos específicos para el gen NS5 que es una región homóloga que codifica la polimerasa, una de las proteínas mejor preservadas en virus de RNA, permitiendo por ello esta técnica amplificar una gran variedad de virus de RNA dentro de este género ${ }^{(18,21)}$. Este estudio fue realizado en sueros de individuos con sospecha clínica de dengue, obteniéndose una buena sensibilidad de 0,2 UFP para detección de estos virus, sin embargo, localmente aún no fue utilizada en la detección de flavivirus en mosquitos ${ }^{(21)}$.

Por ello, el objetivo de este estudio fue la implementación de un sistema de detección de flavivirus en mosquitos colectados en zonas urbanas y rurales de Paraguay entre los años 2016 a 2018. Dentro de este sistema se utilizará un RTnested PCR previamente descripta por Sánchez-Seco et al., 2005 que permitirá la detección género específica a bajo costo, de patógenos de importancia a nivel de salud pública y además permitirá detectar ISFV; cuya investigación, podría contribuir a mejorar la comprensión sobre el ciclo de transmisión de estas virosis ${ }^{(18)}$.

\section{MATERIALES Y MÉTODOS \\ Capacitaciones realizadas}

Para la implementación de técnicas de detección de flavivirus en mosquitos se realizaron capacitaciones previas con profesionales expertos del Instituto de Virología J.M. Vanella de la Universidad Nacional de Córdoba, Argentina. Las capacitaciones consistieron en clases teóricas y prácticas y pasantías de los miembros del equipo de trabajo del IICS-UNA, que fueron llevadas a cabo a través del Proyecto "Vigilancia $\boldsymbol{y}$ caracterización molecular de arbovirus circulantes en Paraguay, Argentina, Uruguay y Brasil", financiado por el Programa de Asociación de Proyectos Conjuntos de Investigación del MERCOSUR. A través de estas capacitaciones se realizó la transferencia de los procedimientos a ser implementados.

Además, las colectas iniciales de mosquitos fueron acompañadas por un profesional experto del Laboratorio de Virología J.M. Vanella y un experto local del Servicio Nacional de Erradicación de Paludismo (SENEPA) y se llevaron a cabo en el marco del Proyecto "Aspectos ecológicos $y$ epidemiológicos de Flavivirus y sus vectores en una zona urbana y rural del Paraguay". Los mencionados profesionales acompañaron todo el proceso desde la selección de lugares apropiados para colocación e instalación de las trampas de mosquitos, correcto almacenamiento, transporte de muestras hasta el lugar de procesamiento, y la preparación de los pools de mosquitos para la posterior realización de técnicas de RT-PCR. Para el registro de datos, así como para el control de transporte y almacenamiento se utilizaron planillas que fueron completadas tanto en el lugar de colecta, como en el IICS-UNA, donde los mosquitos capturados fueron almacenados, para la posterior identificación de las especies de 
mosquitos, formación de los pools y la detección de flavivirus en los mismos. A continuación, se presenta el flujograma de trabajo; (Figura 1).

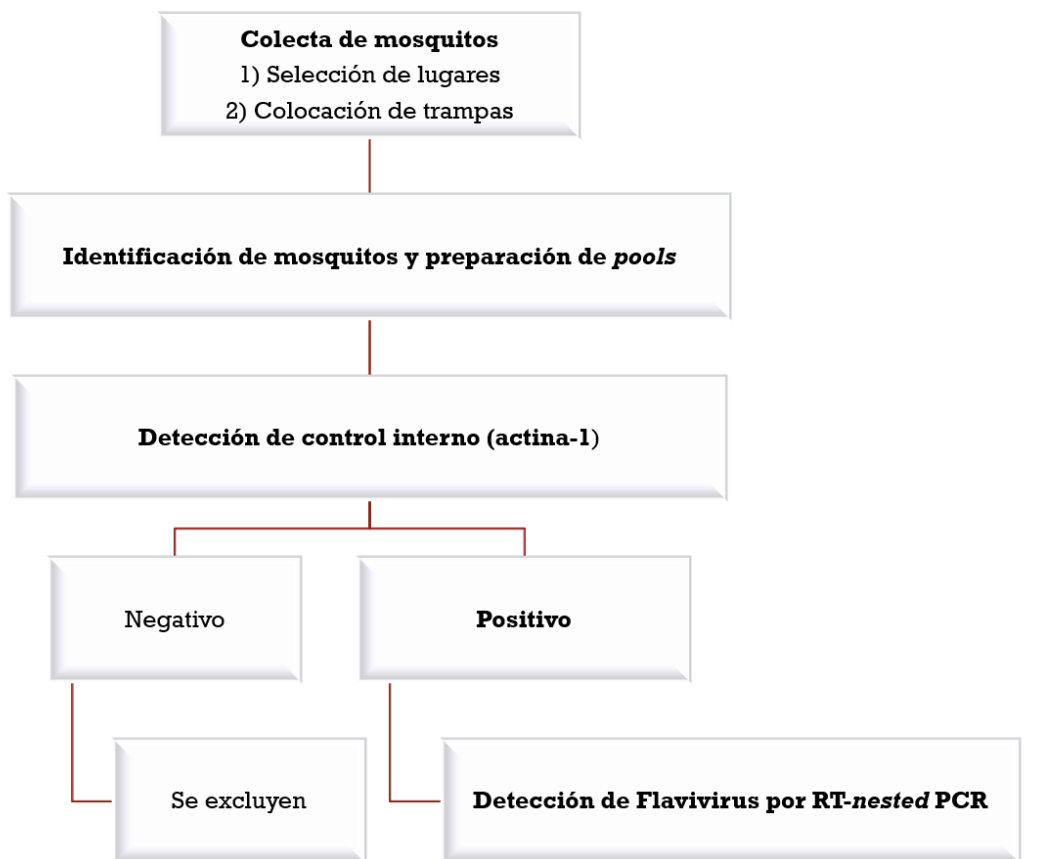

Figura 1. Flujograma de trabajo implementado para la identificación de Flavivirus en el Equipo de Investigación de Arbovirus del IICS-UNA

\section{Población de mosquitos}

Las colectas de mosquitos fueron llevadas a cabo en el marco del Proyecto "Aspectos ecológicos y epidemiológicos de Flavivirus y sus vectores en una zona urbana y rural del Paraguay".

La recolección se realizó mediante la utilización de trampas de luz tipo CDC suplementadas con hielo seco y trampas BG Sentinel del SENEPA. Se colocaron en promedio 8 trampas por colecta las cuales permanecieron activas desde las 18:00 horas hasta las 09:00 horas del día siguiente, aproximadamente. Se realizaron como mínimo 2 noches de captura por localidad y por zonas. Cada trampa se identificó con un código y se registró el lugar donde la instaló, el horario de colocación y retiro de la misma.

Los mosquitos colectados se transportaron refrigerados en hielo seco y/o nitrógeno líquido al IICS-UNA, hasta su procesamiento.

\section{Preparación de pools de mosquitos}

Los mosquitos colectados fueron identificados taxonómicamente en frío según la clave de Darsie ${ }^{(22)}$ por un profesional entomólogo del SENEPA, agrupándose en pools de 1 a 35 mosquitos por especie, localidad, fecha de colecta y estado alimentario (alimentado con sangre, no alimentado con sangre). Estos pools fueron homogenizados en morteros estériles y diluidos en medio esencial mínimo (MEM) suplementado al $10 \%$ con suero fetal bovino (SFB), $1 \%$ con antibiótico (gentamicina) y $1 \%$ con antimicótico (fungizona). Los homogeneizados fueron centrifugados a $11.400 \mathrm{~g}$ durante $30 \mathrm{~min}$ en centrífuga refrigerada para su descontaminación. Los sobrenadantes obtenidos se recuperaron y almacenaron en tubos Eppendorf a $-80^{\circ} \mathrm{C}$ hasta su procesamiento.

\section{Extracción de ARN viral}

La extracción de ARN viral fue llevada a cabo a partir de 200 uL de muestra (pools de mosquitos). Se utilizó el kit comercial NucleoSpin Virus (Macherey Nagel, Alemania) siguiendo las instrucciones del fabricante. EI ARN extraído fue eluído con un total de $30 \mathrm{uL}$ de tampón de elución, almacenados a $-80^{\circ} \mathrm{C}$ hasta su procesamiento.

\section{RT-PCR para detección de ARN de actina-1}

Para evaluar la integridad de los pools de mosquitos extraídos se llevó a cabo una RT-PCR para la detección de ARN de actina-1 descripta por Staley y colaboradores en 
el año $2010^{(23)}$. Solamente los pools con control interno positivo fueron sometidos a la detección de flavivirus.

\section{Búsqueda del genoma de flavivirus mediante RT-nested PCR genérica}

La búsqueda del genoma de flavivirus se realizó a través de la reacción de RTnested-PCR descripta por Sánchez-Seco y col. en el año 2005, previamente implementada en el laboratorio con muestras de suero de pacientes febriles ${ }^{(21)}$. En el presente estudio se utilizaron random primers (Byodinamics, AR) para la retrotranscripción que fue realizada con la transcriptasa reversa Moloney Murine Leukemia Virus (M-MLV) (Promega, EUA). Mientras que los primers específicos constituyeron primers degenerados que amplifican una región conservada que codifica para la proteína NS5 (región parcial NS5) ${ }^{(21)}$. Los productos de amplificación de la nested PCR fueron guardados a $-20^{\circ} \mathrm{C}$ para posterior envío a secuenciación en los casos necesarios.

\section{Secuenciación de productos de amplificación obtenidas de muestras seleccionadas}

Se seleccionaron aleatoriamente pools de mosquito positivos para flavivirus y los fragmentos amplificados por RT-PCR fueron purificados mediante el kit comercial AxyPrep DNA Gel Extraction (Axygen Biosciences, USA) siguiendo las instrucciones del fabricante y posteriormente fueron sometidos a secuenciación nucleotídica por el método de Sanger a través del servicio de la empresa Macrogen (Seoul, Corea del Sur).

Las secuencias de nucleótidos fueron analizadas y editadas con el software BioEdit v7.0.7.0. Las secuencias obtenidas se compararon mediante el algoritmo Basic Local Alignment Search Tool (BLAST) con las secuencias de nucleótidos del gen NS5 de los flavivirus existentes en la base de datos del GenBank del NCBI (http://blast.ncbi.nlm.nih.gov/Blast.cgi) ${ }^{(24)}$.

\section{RESULTADOS}

\section{RT-PCR para detección de ARN de actina-1}

Del total de mosquitos colectados fueron procesados 1803 contenidos en 201 pools. La selección se realizó de acuerdo a las especies de mosquitos reportadas como vectores de arbovirus (principalmente Aedes aegypti, Culex quinquefasciatus, entre otras). Los 201 pools de mosquitos fueron positivos para el control interno (ARN de actina-1) (Figura 2).

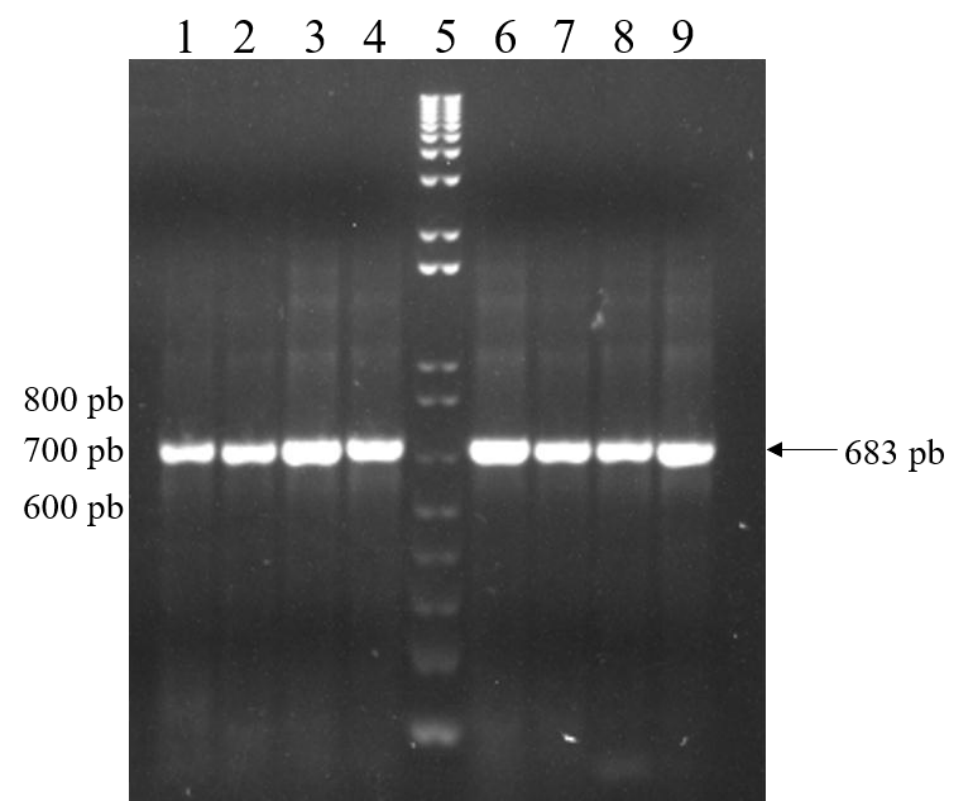

Figura 2: Electroforesis en gel de agarosa al 1,5\% de los productos amplificados para la actina-1. Carriles 1 al 4 y Carriles 6 al 9: muestras de pools de mosquitos sometidos a RT-PCR para el gen de actina-1 donde se observa el tamaño esperado de $683 \mathrm{pb}$ (23). Carril 5: marcador de pares de bases. 
Las 201 muestras fueron sometidas a la detección genérica de Flavivirus descripta por Sanchez Seco y colaboradores, 2005 (18). El 45,2\% (91/201) de los pools analizados fueron positivos siendo los más frecuentemente detectados $(65 / 91 ; 71,43 \%)$ aquellos conformados por Culex quinquefasciatus (Tabla 1, Figura 3 ).

Tabla 1. Frecuencia de muestras positivas para el género Flavivirus por especie.

\begin{tabular}{lrr}
\hline \multicolumn{1}{c}{ Especie } & Frecuencia & \% \\
\hline Culex quinquefasciatus & 65 & 71,43 \\
Aedes aegypti & 17 & 18,68 \\
Culex (Melanoconium) sp. & 5 & 5,49 \\
Ochlerotatus scapularis & 2 & 2,20 \\
Ochlerotatus sp. & 1 & 1,10 \\
Coquilletidia sp. & 1 & 1,10 \\
Total & 91 & 100,00 \\
\hline
\end{tabular}

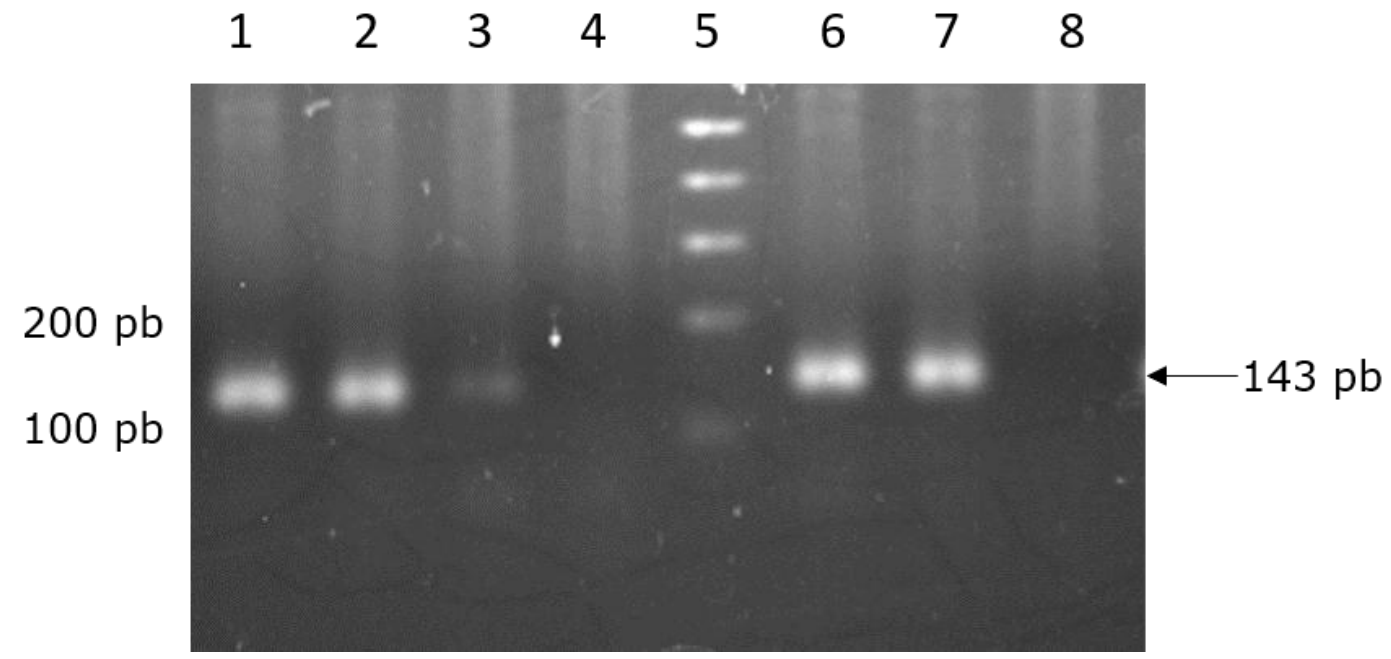

Figura 3: Electroforesis en gel de agarosa al $2 \%$ de los productos amplificados por RT-nested PCR para detección de Flavivirus (21). Carriles 1-4 y 6: muestras de pools de mosquitos sometidos a RT-nested PCR para Flavivirus donde en las muestras positivas $(1,2,3,6)$ se observa el tamaño esperado de $143 \mathrm{pb}$ (18). Carril 5: marcador de pares de bases. Carril 7: Control positivo y Carril 8: Control Negativo.

\section{Secuenciación de muestras positivas para Flavivirus}

Del total de pools positivos, se seleccionaron aleatoriamente 20 muestras positivas para Flavivirus las cuales fueron enviadas para su secuenciación a la empresa Macrogen, Corea. En relación a las secuencias obtenidas a partir de la reacción de RTnested PCR genérica para flavivirus, se obtuvieron fragmentos de secuencias analizables de 78 a $90 \mathrm{pb}$, obteniendo como resultado de BLAST porcentajes de identidades del 91 al $99 \%$ con secuencias de Cell fusion agent virus y otros flavivirus de mosquitos depositadas en el GenBank. No se obtuvo la secuencia de una de las muestras debido a la baja concentración de la misma. En la Figura 4 se pueden observar el resultado del BLAST realizado para uno de los pools. 


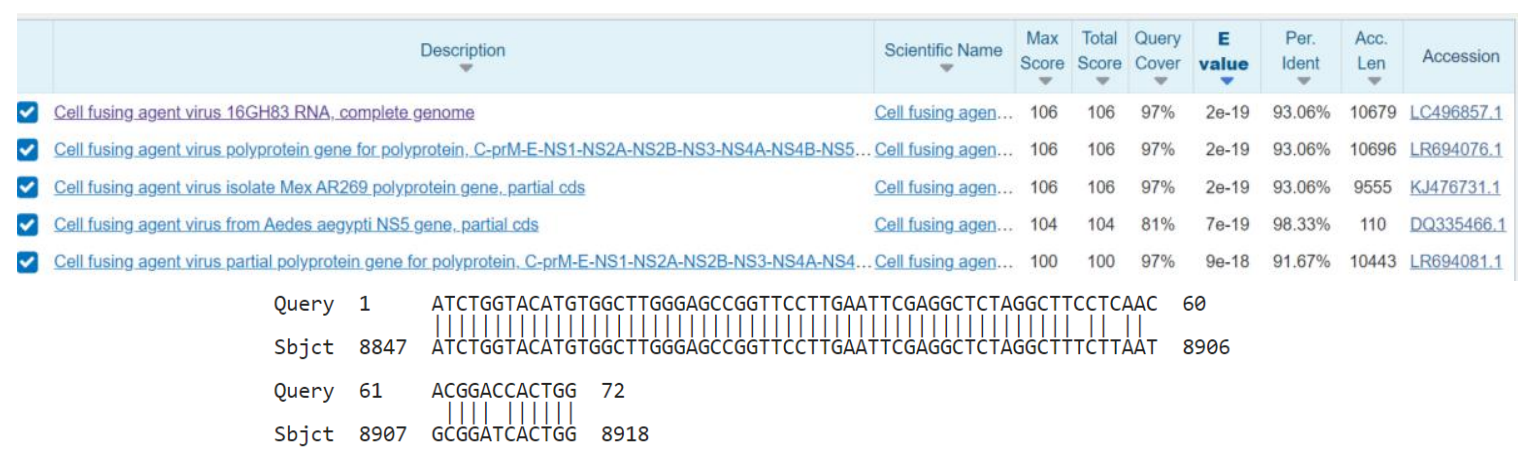

Figura 4: Resultado de alineamiento por BLAST de una secuencia de nucleótidos parcial del gen NS5 de muestra de Aedes aegypti positiva para flavivirus. Se muestran los resultados de BLAST obtenidos de un Pool de mosquito positivo para flavivirus y en la parte inferior el alineamiento con la secuencia con número de acceso del GenBank LC496857.1

De los pools analizados 2/19 correspondieron a CxFV (Ochlerotatus scapularis y Culex quinquefasciatus con un 93 al 97\% de identidad), 17/19 a flavivirus de Aedes aegyti con 91 al $100 \%$ de identidad (virus Kamiti River, virus agente viral de fusión celular, entre otros).

\section{DISCUSIÓN}

Los flavivirus son una preocupación real para la salud pública ${ }^{(18)}$. En este estudio se implementó un sistema de detección de flavivirus en mosquitos.

Las capacitaciones realizadas de los profesionales locales, el cumplimiento de los procedimientos, registro de datos, así como controles utilizados (control interno, positivo y negativo) en las técnicas de RT-PCR convencionales, facilitaron considerablemente la implementación del sistema de detección de flavivirus en mosquitos en el IICS-UNA.

En la selección de la técnica de RT-PCR para detección de flavivirus se tuvo en cuenta que la misma sea rápida, simple y detecte un amplio número de patógenos con elevada sensibilidad. Para ello se utilizó la RT-nested PCR descripta por Sánchez-Seco y col., 2005 que usa primers universales género-específico que permiten la detección teóricamente de todos los virus que se encuentran dentro del género Flavivirus de importancia médica o ecológica como los flavivirus de insectos, con una buena sensibilidad, posibilitando el diagnóstico y vigilancia de un número mayor de infecciones, optimizando de este modo el uso de recursos ${ }^{(4,18,21,25)}$. Además, podría emplearse para establecer el agente causal de brotes de manera eficiente, ya que el producto de amplificación obtenido en la nested PCR de 143 pb por secuenciación permite identificar de qué flavivirus se trata ${ }^{(16)}$. Otra ventaja es que la primera reacción (RT- PCR) también puede ir combinada con una nested PCR con primers específicos que permitan identificar flavivirus de importancia médica como DENV 1-4 utilizando los productos de amplificación de la primera reacción descripta por SanchezSeco et al., $2005^{(18,19)}$.

Todos los pools de mosquitos preparados fueron sometidos a la detección de ARN de actina-1 como control interno. La detección de este control interno en todos los pools testeados demuestra que el proceso de preparación y de extracción de los mismos fue óptimo ${ }^{(23,25)}$.

Además, $91 / 201(45,2 \%)$ pooles fueron positivos para Flavivirus a partir de RTnested PCR. 19 pools fueron secuenciados, identificándose en los mismos ISFV. Ambos resultados mencionados anteriormente indican la exitosa implementación de la técnica de detección de flavivirus en pools de mosquitos. Pero como ya fue mencionado es necesaria la utilización combinada de otras técnicas como la secuenciación o la realización de RT-PCRs específicas para la identificación específica de la especie de Flavivirus. Otra de las ventajas es que las PCRs específicas pueden realizarse a través del cDNA obtenido por la transcripción reversa ${ }^{(20)}$. 
Además, la elevada detección de ISFV en este estudio y la alta prevalencia reportada previamente en mosquitos de Paraguay y Brasil ${ }^{(25)}$, sugieren una amplia circulación de los ISFV (principalmente de CXFV), por lo cual sería de utilidad la implementación de técnicas para detección de los mismos, las cuales podrían ser incorporadas dentro del sistema de detección de flavivirus propuesto en el presente estudio, a fin de facilitar la identificación de potenciales pools de mosquitos positivos para flavivirus de importancia médica.

Si bien los flavivirus de insectos no son causantes de enfermedades, los mismos presentan nuevas oportunidades en la evolución viral, en el estudio de la interacción virus/vector y además tienen un enorme potencial como agentes para el control biológico de vectores de importancia médica ${ }^{(26)}$.

En conclusión, el presente estudio ha permitido la implementación de un sistema de detección de flavivirus, el cual podrá ser utilizado para explorar infecciones virales en mosquitos que actúan como vectores de flavivirus de importancia médica (DENV, ZIKV, SLEV, etc.) y también los ISFV, con miras a un mayor conocimiento de la distribución de estos virus en nuestro país y en la región, constituyendo así una herramienta de importancia para la vigilancia y el control de la transmisión de estos virus.

\section{AGRADECIMIENTOS}

Se agradece el apoyo de las autoridades del IICS-UNA y de SENEPA en la realización del trabajo. Un agradecimiento especial a la Lic. Nidia Martínez (QEPD), brillante profesional, quien, en calidad de Jefa del Departamento de Entomología, SENEPA, brindó su apoyo técnico, el cual fue esencial para la realización del presente trabajo.

FUENTE DE FINANCIAMIENTO: Este proyecto fue financiado por el CONACYT a través del Programa PROCIENCIA con recursos del Fondo para la Excelencia e Investigación - FEEI del FONACIDE (14-INV-152).

\section{No se declaran conflictos de interés.}

\section{CONTRIBUCIONES DE LOS AUTORES}

Idea: Cardozo F, Mendoza L

Elaboración del proyecto: Cardozo F, Díaz A, Contigiani M, Mendoza L.

Metodología y recolección de datos: Cardozo $F$, Rojas $A$, Bernal $C$, Ferreira L, Díaz A, Páez M, Guillén Y, Contigiani M, Mendoza L.

Redacción (borrador original): Cardozo F, Mendoza $L$

Análisis de datos, discusión, conclusiones, y aprobación para publicación: Cardozo F, Rojas A, Bernal C, Ferreira L, Díaz A, Páez M, Guillén Y, Contigiani M, Mendoza L.

\section{REFERENCIAS BIBLIOGRÁFICAS}

1. ICTV Virus Taxonomy 2014 [Internet]. [citado 11 de agosto de 2015]. Disponible en: http://www.ictvonline.org/virusTaxono my.asp

2. Bhatt S, Gething PW, Brady OJ, Messina JP, Farlow AW, Moyes CL, et al. The global distribution and burden of dengue. Nature. 2013 Apr 25; 496(7446):504-7.

3. Pierson TC, Diamond MS. The continued threat of emerging flaviviruses. Nat Microbiol 5, 796-812 (2020).

4. Scaramozzino N, Crance J-M, Jouan A, DeBriel DA, Stoll F, Garin D. Comparison of Flavivirus Universal
Primer Pairs and Development of a Rapid, Highly Sensitive Heminested Reverse Transcription-PCR Assay for Detection of Flaviviruses Targeted to a Conserved Region of the NS5 Gene Sequences. J Clin Microbiol. 5 de enero de $2001 ; 39(5): 1922-7$.

5. Calzolari $M$, Zé-Zé $L$, Vázquez $A$, Sánchez Seco MP, Amaro F, Dottori M. Insect-specific flaviviruses, a worldwide widespread group of viruses only detected in insects. Infect Genet Evol. 1 de junio de 2016; 40:381-8.

6. Young PR. Arboviruses: A Family on the Move. Adv Exp Med Biol. 2018;1062:110. 
7. Martín Acebes MA, Saiz JC. Flavivirus que infectan el sistema nervioso. Artículo de revisión. Virologia. 2012; 15:58-64.

8. Contigiani MS. Virología. Flaviviridae. Cap 91. En: Microbiología Biomédica: bacteriología, micología, virología, parasitología, inmunología. 2da Edición. Buenos Aires: Editorial Atlante S.R.L.; 2010. p. 905-9.

9. Tauro L, Marino B, Diaz LA, Lucca E, Gallozo D, Spinsanti L, et al. Serological detection of St. Louis encephalitis virus and West Nile virus in equines from Santa Fe, Argentina. Mem Inst Oswaldo Cruz. junio de 2012;107(4):553-6.

10. Diaz LA, Komar N, Visintin A, Juri MJD, Stein $M$, Allende $R L$, et al. West Nile Virus in Birds, Argentina. Emerg Infect Dis. abril de 2008; 14(4):689-91.

11. Pauvolid-Corrêa A, Morales MA, Levis S, Figueiredo LTM, Couto-Lima D, Campos $Z$, et al. Neutralising antibodies for West Nile virus in horses from Brazilian Pantanal. Mem Inst Oswaldo Cruz. junio de 2011 ; 106(4): 467-74.

12. Pereira LE, Suzuki A, Coimbra $T L$, de Souza RP, Chamelet EL. [Ilheus arbovirus in wild birds (Sporophila caerulescens and Molothrus bonariensis)]. Rev Saúde Pública. abril de 2001; 35(2):119-23.

13. WHO. Outbreak News: Yellow Fever, Paraguay. Weekly Epidemiological Record. 2008; (83): 105-8.

14. Stein M, Oria GI, Almirón WR. Main breeding-containers for Aedes aegypti and associated culicids, Argentina. Rev Saúde Pública. octubre de 2002;36(5):627-30.

15. MSPyBS. Dirección General de Vigilancia de la Salud. Boletín epidemiológico semanal. 49a ed. 2011;

16. Díaz LA, Albrieu Llinás $G$, Vázquez $A$, Tenorio A, Contigiani MS. Silent Circulation of St. Louis Encephalitis Virus Prior to an Encephalitis Outbreak in Cordoba, Argentina (2005). PLoS Negl Trop Dis [Internet]. 31 de enero de 2012 [citado 27 de noviembre de 2014]; 6(1). Disponible en: http://www.ncbi.nlm.nih.gov/pmc/articl es/PMC3269431/

17. Peeling RW, Artsob $\mathrm{H}$, Pelegrino $\mathrm{JL}$, Buchy $\mathrm{P}$, Cardosa MJ, Devi S, et al. Evaluation of diagnostic tests: dengue. Nat Rev Microbiol. 2010 Jan; 8:S30-7.

18. Sánchez-Seco MP, Rosario D, Domingo C, Hernández L, Valdés K, Guzmán MG, et al. Generic RT-nested-PCR for detection of flaviviruses using degenerated primers and internal control followed by sequencing for specific identification. J Virol Methods. 2005 Jun; 126(1-2): 101-9.

19. Sánchez-Seco MP, Rosario D, Hernández L, Domingo $C$, Valdés $K$, Guzmán MG, et al. Detection and subtyping of dengue 1-4 and yellow fever viruses by means of a multiplex RT-nested-PCR using degenerated primers. Trop Med Int Heal TM IH. 2006 Sep; 11(9):1432-41.

20. Bronzoni RV de M, Baleotti FG, Nogueira RMR, Nunes M, Figueiredo LTM. Duplex Reverse Transcription-PCR Followed by Nested PCR Assays for Detection and Identification of Brazilian Alphaviruses and Flaviviruses. J Clin Microbiol. 2005; 43(2):696.

21. Cardozo-Segovia FM, Rojas-Segovia AM, Franco L, Herebia L, Vallejos MA, Páez-Acchiardi GM, et al. Search of flavivirus in individuals with clinical suspicion of dengue and negative for the NS1 antigen in Paraguay. Mem Inst Investig En Cienc Salud. 30 de abril de 2017; 15(1):7-15.

22. Darsie R. MOSQUITOES OF ARGENTINA. 3a ed. Vol. 17. 1985. $101 \mathrm{p}$.

23. Staley M, Dorman KS, Bartholomay LC, Fernández-Salas I, Farfan-Ale JA, Loroño-Pino MA, et al. Universal primers for the amplification and sequence analysis of actin-1 from diverse mosquito species. J Am Mosq Control Assoc. junio de 2010; 26(2):214-8.

24. Hall TA. BioEdit: a user-friendly biological sequence alignment editor and analysis program for Windows 95/98/NT. Nucleic Acids Symp Ser. 1999; 41:95-8.

25. Gravina HD, Suzukawa AA, Zanluca C, Cardozo Segovia FM, Tschá MK, Martins da Silva $A$, et al. Identification of insectspecific flaviviruses in areas of Brazil and Paraguay experiencing endemic arbovirus transmission and the description of a novel flavivirus infecting Sabethes belisarioi. Virology. 15 de enero de 2019; 527:98-106.

26. Roundy CM, Azar SR, Rossi SL, Weaver SC, Vasilakis N. Insect-Specific Viruses: A Historical Overview and Recent Developments. Adv Virus Res. 2017; 98:119-46. 